\title{
Just Your Voice - A Voz Como Mediador Privilegiado na \\ Clínica com Bebês em Risco PaRa Autismo e na CLínica Com \\ Crianças Autistas
}

Inês Catão 1

\section{RESUMO}

A partir da noção psicanalítica de voz, da hipótese de que ela é o primeiro objeto em torno do qual se organiza o laço da criança com o Outro, e da hipótese de que a clínica do autismo testemunha uma dificuldade específica na constituição do circuito da pulsão invocante e do objeto voz, este artigo trata do manejo desta pulsão e da voz como mediadores privilegiados na clínica com bebês em risco para autismo e na clínica com crianças autistas.

PALAVRAS-CHAVE: psicanálise, bebês, autismo, voz, pulsão invocante.

1 Psicanalista membro da Escola Letra Freudiana (RJ), médica psiquiatra infantil (SESDF), Pós Doutora em Psicopatologia pela Universidade Côte d'Azur (França), autora do livro O bebê nasce pela boca: voz, sujeito e clínica do autismo (SP: Instituto Langage) e de numerosos artigos publicados em revistas e livros especializados no Brasil e na França, escritora. Endereço de correspondência: SQN 215 bloco k apto 205 Asa Norte Brasília DF CEP 70 874-110. Email: cataoines@gmail.com.

13 Psicanálise \& Barroco em revista | v.17, n. 01 | julho de 2019 
"O sujeito produz a voz. E direi mais, teremos que envolver esta função da voz, no que diz respeito ao peso do sujeito, o peso real do sujeito no discurso." (LACAN, Seminário livro 6)

\section{Apenas a Sua Voz}

Owen Suskind foi diagnosticado autista aos 3 anos de idade. Seus pais Ron e Cornellia comentam que "seu filho desapareceu, foi sequestrado". Deixou de falar, ensimesmou-se, passou a dedicar seu tempo a assistir filmes da Disney e a editá-los. Repetia ecolalicamente frases consideradas sem sentido pelos médicos procurados por seus pais. Certo dia, a mãe teve a impressão de compreender algo no que o filho dizia. Ela pensou ter escutado a palavra "juice". Interrogou o filho se ele queria suco, sem resultado. Então reparou que, na verdade, o que ela ouvia, era a repetição de um trecho do filme $A$ pequena sereia, aquele em que a Medusa Malvada diz à ela que pode torna-la humana. Para isso, a pequena sereia tem que Ihe dar apenas a sua voz: just your voice.

O fato da mãe ter encontrado um sentido no que o filho dizia, validando sua fala no código da língua, iluminou o pequeno Owen, que começou a sair do seu fechamento autístico. $O$ pai descobriu também que o filho, que não respondia às pessoas, respondia ao fantoche do papagaio do filme Peter Pan. A família passou a falar com a criança através de diálogos encenados dos filmes da Disney. A descoberta levou os pais de Owen a propor a Affinity Therapie, uma Terapia por Afinidade.

Lacan, na Conferência de Genebra sobre o Sintoma (1975), diz que os autistas são personagens verbosos, e que se eles falam, repetem o que ouviram em algum lugar. Que não saibamos dar sentido ao que eles dizem, não os impede de serem verbosos. Os pais de Owen, sem terem lido Lacan, colocaram-se em relação ao filho na posição de analista - sujeito suposto saber que há sujeito (VIVÈS, 2012) validando o que ouviam.

Não é por acaso que Owen recorta esta passagem específica do filme, uma passagem que fala sobre como tornar-se humano. Sabemos de interesse semelhante em crianças autistas fixadas, por exemplo, na história do Pinóquio, o boneco de madeira que virou um menino. Mas o recorte feito por Owen é ainda mais emblemático do que parece ocorrer no autismo: uma dificuldade específica com a voz. 
Just Your Voice - A Voz Como Mediador Privilegiado Na Clínica Com Bebês Em

Risco Para Autismo E Na Clínica Com Criançãs Autistas

\section{No Começo Era Voz...}

Em “O Ego e o Id” (1977[1923]), Freud sublinha a importância do que entra pela calota acústica, para a formação do aparelho psíquico. O que entra pelos ouvidos, orifícios que nunca se fecham, faz marca, que vira traço, que vira significante, que se organiza em cadeia, cujo produto é o sujeito e o resto é o objeto a que faz mover a cadeia. Freud já tinha dado importância à voz tanto na organização psíquica quanto ao falar da constituição do supereu como instância vocal - as vozes do supereu - e ao propor as bases da cura analítica, uma cura pela fala.

Coube, no entanto, a Lacan dar um lugar ainda mais privilegiado à voz em seu ensino como uma das apresentações do objeto a. Ele ampliou a lista freudiana de objetos pulsionais - seio e fezes, objetos da demanda -, incluindo voz e olhar, objetos do desejo. Em Lacan, a voz se torna o objeto da pulsão invocante, aquela a que ele se refere como "a mais próxima do inconsciente" (LACAN, 1985). A voz é o objeto do desejo do Outro.

Há uma disjunção entre o que se entende por voz no senso comum e o que, com Lacan, é considerado voz para a psicanálise. Aqui, ela não se confunde com o som. O som pode servir de vestimenta imaginária da voz, não sendo, no entanto, a única. A voz está presente também no silêncio, em todos os modos de vibração e em todos os modos de mútuo endereçamento entre o sujeito e o Outro, sendo o endereçamento a sua marca.

A palavra, o sentido, constituem a dimensão simbólica da voz. Mas, a voz propriamente dita, em Lacan, é áfona e não tem compromisso com a significação. Ela é o objeto vazio da pulsão em torno do qual se organiza o primeiro laço com o Outro, sob a forma de um circuito pulsional em três tempos: "chamar" (o grito), "ser chamado" (pela mãe) e "se fazer chamar" (se implicar no laço).

A audição é um sentido que se encontra constituído desde o quinto mês de gestação. O bebê ouve a voz da mãe desde intra útero - o que implica não apenas som mas vibração -, e reage à ela com movimentos. Ele é capaz de reconhecer esta voz desde que nasce, mesmo se retransmitida por um gravador. As experiências dos psicolinguístas mostraram que antes de qualquer leite para saciar a fome, o bebê se alimenta da voz da mãe.

Sua principal sede é de interação com o outro, talvez fruto de seu desamparo ao nascer. Ele busca ativamente por esta interação. O bebê se coloca como um parceiro ativo nas trocas vocais que estabelece com o outro, mesmo se não

Psicanálise \& Barroco em revista | v.17, n. 01 | julho de 2019 
compreende ainda as palavras pronunciadas. Mas não basta a apetência para o laço. O estabelecimento do vínculo com o semelhante implica perdas.

Em "A Pequena Sereia”, a Medusa Malvada indica o caminho da perda necessária à humanização. A sereia teria que consentir em perder seu bem mais precioso, sua voz encantatória, para poder falar, deixando assim de ser...eia. Com os seres humanos acontece algo semelhante. Para passar à condição de sujeito, isto é, poder contar com uma organização psíquica e com a função da fala na sua circulação no campo da linguagem, o bebê deve consentir em perder algo do ser. A passagem de infante a ser falante implica deixar o reino do som pelo reino do sentido.

Lacan nomeou de alienação e separação as duas operações constitutivas do sujeito que ocorrem em tempos lógicos. A alienação corresponde ao passo que a criança dá aceitando perder o gozo sonoro da voz em prol da sincronia com a musicalidade da fala materna. A separação nomeia o passo que conduz a criança, por meio da sincronia musical, à incorporação do vazio da voz, tornado objeto da pulsão. No processo de constituição psíquica, o bebê perde a possibilidade de escutar a própria voz e, também, de falar todas as línguas.

Para Maleval (2017), o autista não cede sobre o gozo vocal. Sua dificuldade não é com o registro sonoro da voz, mas com o dizer. O autista tenta fazer um uso da voz que escape à enunciação. Jean-Michel Vivès (2012) faz a hipótese da não constituição do ponto surdo, cicatriz do recalque originário, que no autismo não acontece. M.-C. Laznik (2014) propõe que no autismo falha o fechamento do terceiro tempo do circuito pulsional, tempo dito passivo, no qual o bebê se oferece no lugar de objeto de gozo do outro, compartilhando prazer e, ao fazê-lo, demonstrando que aceitou o jogo de entrada na linguagem. O autista não faz o fechamento do terceiro tempo da pulsão porque recua diante do mútuo endereçamento que lhe aponta, no

horizonte, o buraco. No autismo, a voz não se constitui enquanto objeto vazio da pulsão, algo falha na incorporação primordial, como propomos.

A clínica do autismo mostra as inúmeras estratégias de que a criança lança mão para lidar com a voz. Mutismo, sonorização, ecolalias, holófrases, uso de uma língua estrangeira em lugar da língua materna, dentre outros, são modos de defesa do autista no que tange o objeto voz.

A marca do autismo é a recusa radical e precoce ao que vem do campo do Outro. Esta recusa aparece na clínica em vários registros. Ao contrário da maioria dos bebês, 
Just Your Voice - A Voz Como Mediador Privilegiado Na Clínica Com Bebês Em

Risco Para Autismo E Na Clínica Com Criançãs Autistas

sua alienação ao campo da linguagem é feita com reservas. Ela traz a marca de uma recusa.

\section{O Canto da Sereia Materno e a Constituiç̧̃̃o Do Sujeito}

O laço com o agente materno é a condição si ne qua non para que a criança organize um funcionamento pulsional em três tempos. O vínculo é uma co-construção entre mãe e criança. Vivès (2019) aponta, de modo pertinente, que a prosódia manhês é co-construída também.

A função materna implica, em um primeiro momento, um chamado para o vínculo. A criança precisa dar ouvidos ao canto da sereia materno. Ela deve poder deixar-se encantar pela melopéia da voz da mãe, dar seu sim à ela, para depois ensurdecer a este chamado, como condição de constituir a própria voz.

Didier-Weill $(1997,2014)$ diz sobre a música que não é o sujeito que a ouve, é ela que o escuta. É por sentir-se escutado por ela, que nada the pede, que ele aquiesce com o encontro musical. O que a música devolve a quem a ouve é o próprio enigma do sujeito, de modo invertido. O sujeito passa assim de ouvinte a invocante. Talvez seja por isso que a maior parte dos sujeitos gosta de música, por sentir-se acolhido por ela.

Da mesma maneira, a musicalidade da fala materna não demanda nada à criança. Ela acolhe o grito do bebê, que assim não cai no vazio. O bebê é escutado pela musicalidade da fala materna. Esta retorna para ele que se reconhece como autor naquele que chama e que é chamado. Passando a invocante, ele se faz chamar.

Nos anos 80, a psicolinguísta Anne Fernald estudou o interesse do bebê pela voz da mãe. Ela se perguntou o que o interessava aí. Descobriu espanto e grande prazer como marcas da prosódia manhês. Todo bebê se interessa por este tipo específico de prosódia, inclusive aquele que vai posteriormente receber o diagnóstico de autismo.

Laznik (2004) propôs que estas duas características do manhês equivalem aos dois tempos do chiste descritos por Freud (FREUD,1977/1905): sideração e luz. Ela conclui que a prosódia manhês interessa os bebês por transmitir o modo de gozo materno. Podemos dizer que um bebê ao nascer se alimenta deleite. Que haja um desejo não anônimo endereçado à criança e um gozo suscitado no outro por sua presença é fundamental para que o bebê se tome pelo objeto deste gozo, constituindo assim a alienação. 
Vivès (2019) propõe responder de outro modo a questão sobre o que torna irresistível a voz da mãe para todo bebê. Para ele, "a fala Ihe é transmitida enquanto frequentada pelo timbre da voz materna." O timbre "é insubstituível e representa o sujeito que o porta para aquele que o escuta... O que torna uma voz singular não é o que ela diz, nem como diz, mas seu timbre, que é a dimensão real da voz sonora." Para Vivès, é o timbre da voz que orienta o bebê em direção à mãe. É ele que o levará a alienar-se ao campo da linguagem. Vivès faz do timbre da voz materna a isca que o bebê deve fisgar para ser apanhado pelo anzol da linguagem. Tomando esta hipótese, propomos que aquilo que aproxima a maior parte dos bebês de sua mãe, o real de sua voz, é o que afasta o bebê futuro autista do encontro com o outro.

\section{IDENTIFICAÇÃo Primordial: O Que Se InCORPORA}

"A psicanálise conhece a identificação como a primeiríssima manifestação de um laço de sentimento a uma outra pessoa2" (FREUD, 1977/1921, p. 133). A operação fundadora do sujeito é a alienação ao campo do Outro e a identificação é a forma privilegiada de sua efetuação.

A identificação primordial é a matriz da série de identificações. Freud propõe que a primeira é identificação por incorporação (Einverleibung) (FREUD, 1977/1921). A identificação por incorporação é a condição que possibilita as duas outras.

Aquilo que se incorpora neste tempo imemorial não é matéria e sim algo que da estrutura se sustenta como incorpóreo (CRUGLAK, 2001). O que na palavra do outro se endereça ao bebê e o captura no campo da linguagem não é o sentido do que é dito mas a dimensão incorpórea da sua voz (na proposta de Vivès, o timbre).

No tempo da identificação primordial o que se incorpora é vazio que, por efeito desta mesma incorporação, institui um lugar vazio. Este vazio será estrutural e estruturante do sujeito, como Lacan explica ao abordar a superfície topológica do toro. "A voz não é assimilada, mas incorporada. É isso que pode servir de modelo para nosso vazio. " (LACAN, 1962, p. 301). Para deixar o reino do som em prol do reino do sentido, o bebê deve poder aceitar identificar-se ao lugar vazio que o Outro the oferece. A mãe implanta no futuro sujeito um vazio, não sem a sua aceitação.

\footnotetext{
${ }^{2}$ Utilizamos aqui a proposta de tradução do texto de Freud "Psicologia das massas e análise do eu", mais especificamente do "Capítulo VII: A identificação" feita por Eduardo Vidal para trabalho interno em 2014-2015 para a Escola Letra Freudiana.
}

18 Psicanálise \& Barroco em revista | v.17, n. 01 | julho de 2019 
Just Your Voice - A Voz Como Mediador Privilegiado Na Clínica Com Bebês Em Risco Para Autismo E Na Clínica Com Criançãs Autistas

Fazemos a hipótese de um comprometimento da identificação primordial nos autismos, pelo viés de uma recusa do real da voz. A incorporação de um lugar vazio se ocorre, se dá de outro modo. A marca deixada pelo encontro com o significante não pode se ordenar em cadeia. A cicatriz da marca constituinte não tem simbolização. O autista não sabe o que fazer com ela. O sujeito não entra no discurso. Nos autismos falta a marca da incorporação da falta.

\section{Sobre O Manejo Clínico da Voz: Reanimação Psíquica, Voz Maquínica, Voz Artificial, fraseado Musical E Voz Monocórdica}

A descoberta de Laznik sobre o manhês como veículo de desejo e gozo maternos lhe permitiu propor o uso desta prosódia na clínica com bebês com meses de vida, em risco para autismo, trabalho que a autora vem nomeando, desde 2012, de reanimação psíquica (SILVA, 2013). Laznik esclarece que não se trata de um conceito, mas de uma descrição fenomenológica. Partindo de sua hipótese do não fechamento do terceiro tempo do circuito pulsional no autismo, ou seja, da impossibilidade do bebê futuro autista se oferecer no lugar de objeto de gozo do outro, se estes bebês partilham essa dificuldade, Laznik se pergunta: se conseguirmos fazêlos entrar nesse jogo, isso modifica o seu prognóstico?

O uso da prosódia manhês com bebês em risco para autismo no primeiro ano de vida, não é uma finalidade em si, não se trata de uma técnica, mas de um mediador privilegiado no manejo clínico. Esta mediação, não se funda no uso do significante, mas na fundação da significância, possibilitando a alienação ao campo da linguagem e a instalação de uma matriz simbolizante no bebê. Ainda assim, o uso dos significantes surgidos em sessão (entre mãe e psicanalista) não é arbitrário, e sim fruto de uma escuta analítica. Indicando a sutileza deste trabalho, Laznik comenta que há um momento propício à intervenção, ao chamamento melódico do bebê: "A escuta do momento onde isso é possível demanda [da parte do analista] uma grande competência de encontrar os momentos em que o bebê é capaz de ser submetido e como captá-lo" (apud SILVA, 2013, p. 140).

$\mathrm{Na}$ reanimação psíquica, o analista não pede a voz do bebê. Ele oferece a musicalidade da sua. Trata-se de restabelecer a sintonia afetiva (STERN, 1992) entre sujeito e Outro, mãe e bebê, mediada pelo analista. Laznik não preconiza o mesmo tipo de manejo clínico com crianças autistas maiores, nem com crianças psicóticas. $O$ trabalho de pôr em funcionamento o terceiro tempo do circuito pulsional, por hipótese 
comprometido no autismo, se destina à clínica com bebês menores de 1 ano e seus pais. A reanimação psíquica também não se aplica à clínica com bebês com distúrbios do vínculo, que não se encontram em risco de fechamento autístico.

O trabalho com crianças autistas maiores de 1 ano de idade, em que o quadro clínico já se encontra mais cristalizado - o que corresponde à maior parte das crianças que chegam até nós no Brasil hoje - terá que valer-se de outras estratégias, indicadas pela própria criança. Trata-se aqui de uma direção que conduza a criança autista de uma impossível cessão do objeto voz ao investimento possível de uma voz (ORRADO, PILAS, VIVÈS, 2017).

A criança autista lança mão de estratégias de borramento subjetivo da voz, a sua própria e a do outro. Ou, para dizer de um outro modo, estratégias de borramento do que, na voz, aponta o coração do sujeito. Na proposta de Vivès, o timbre. Tapar os ouvidos; distorcer as qualidades da própria voz ao falar; distorcer as vozes de um filme ou desenho animado; falar com utilização de fraseado musical; falar em tom monocórdio e responder ao outro apenas quando este se utiliza do mesmo expediente; aceitação preferencial da voz artificial ${ }^{3}$ e da voz maquínica, produzida por um robô "serão utilizadas pelo autista para jogar com essa dimensão do timbre, permitindo uma abertura em direção à linguagem" (ORRADO, PILAS, VIVĖS, 2017, p. 496).

Na clínica psicanalítica com o autista maior, o analista inventa modos de apagar sua presença, se utilizando de sua voz sem se endereçar diretamente à criança e sem olha-la, ao contrário do que é feito na reanimação psíquica de bebês, proposta por Laznik.

\section{Conclusão: Just Your Voice? O Preço De Tornar-Se Sujeito}

A voz é desde Freud um mediador privilegiado na clínica psicanalítica. Por sua importância na estruturação psíquica, encontra-se também implicada de muitas maneiras na psicopatologia. O quadro clínico do autismo resulta da impossibilidade de ceder sobre o gozo da voz.

Em bebês em risco de autismo, por se encontrarem em um impasse nos tempos iniciais da constituição subjetiva, a direção de tratamento visa o chamamento musical para a alienação ao campo da linguagem. Por suas características, a música

\footnotetext{
${ }^{3}$ Voz artificial é o nome dado neste contexto a todo material sonoro vocal, registrado, fixado em um suporte e depois restituído ou transmitido por um meio.

20 Psicanálise \& Barroco em revista | v.17, n. 01 | julho de 2019
} 
é em geral mais facilmente aceita que a palavra. A musicalidade da prosódia manhês traz o apelo de toda música, a marca de um desejo não-anônimo e do gozo maternos. Trata-se aqui de um trabalho com a significância, mais que do que com os significantes, como construção de uma matriz simbolizante que antecede a aquisição, posterior, da língua materna. $\mathrm{Na}$ reanimação psíquica, privilegia-se o registro imaginário (sonoro) da voz que, no entanto, continua a servir de veículo ao real da voz.

Já na clínica com bebês com outro tipo de dificuldades de vínculo, o manejo clínico pede a aposta na palavra dirigida tanto à mãe quanto ao bebê. Escutar a mãe e ler o bebê é aqui precioso, como indicador do que pode estar sendo um impasse no vínculo e "causador" dos sintomas que a pequena criança apresenta.

Dar apenas a sua voz, Just your voice, é imperativo categórico que cada sujeito escuta e ao qual responde como pode: as afasias, gagueiras e mutismos eletivos do neurótico; as alucinações e delírios psicóticos; os medos de barulho, mutismos e ecolalias autistas que nos mostram que dar a voz é um preço que nem toda criança pode pagar para tornar-se sujeito.

O analista escuta estes (des)caminhos e empresta a sua voz, muitas vezes através de seu silêncio, dando voz ao sujeito, ao invés de pedir à ele que fale. 


\section{REFERÊNCIAS}

CRESPIN, G. (2016) “D'un préalable à tout traitement possible des enfants autistes hors langage”. In Coleção Cadernos Preaut número 1 (no prelo).

CRUGLAK, C. Clínica da identificação. RJ: Companhia de Freud. 2001.

DIDIER-WEILL, A. Nota Azul: Freud, Lacan e a Arte. RJ: Contracapa, 2014.

DIDIER-WEILL, A. Os três tempos da lei: o mandamento siderante, a injunção do supereu e a invocação musical. RJ: Zahar, 1997.

FREUD, S. (1977/1905). Os chistes e sua relação com o Inconsciente. In Edição Standard Brasileira das Obras Psicológicas Completas. Rio de Janeiro: Imago. Vol. VIII

FREUD, S. (1977/1921). Psicologia das massas e análise do Eu. Capítulo VII: A identificação". In Edição Standard Brasileira das Obras Psicológicas Completas. Rio de Janeiro: Imago. Vol. XVIII.

FREUD, S. (1977/1923). O Ego e o Id. Edição Standard Brasileira das Obras Psicológicas Completas, Rio de Janeiro: Imago. Volume XIX

LACAN, J. (1958-59). O Seminário, livro 6: o desejo e sua interpretação. RJ: Zahar. 2016.

LACAN, J. (1957-58). O Seminário 5, livro 5: as formações do inconsciente. RJ: Zahar, 1999.

LACAN, J. (1964). O Seminário, livro 11: os quatro conceitos fundamentais da psicanálise. RJ: Zahar, 1985.

LACAN, J. (1962). O seminário, livro 10: a angústia. Rio de Janeiro: Zahar, 2005.

LACAN, J. (1975). Conferência em Genebra sobre o sintoma (1975). Opção Lacaniana, no 23, dezembro, 1998. p. 6-16.

LAZNIK, MAESTRO, MURATORI, PARLATO. Les interactions sonores entre les bébés devenus autistes et leurs parents. In Au commencement était la voix. Toulouse: Érès, 2010.

LAZNIK, M.-C. (2004) A voz como primeiro objeto da pulsão oral. In A voz da sereia: o autismo e os impasses na constituição do sujeito. Salvador: Ágalma.

LAZNIK, M.-C. (2007) La prosodie avec les bébés à risque d'autisme: clinique et recherche. In Langage, voix et parole dans l'autisme. Paris: PUF. p.181-216.

MALEVAL, J.-C. (2017). O autista e sua voz. SP: Blucher.

ORRADO, I. e VIVES, J.-M. (2016) Oficinas terapêuticas: uma mediação para cada um. Texto inédito, apresentado em 19 de agosto de 2016 na "Jornada com Jean-Michel-Vivès: autismo e voz maquínica” realizada por Outrarte (IEL-UNICAMP) e LaPSuS (FCM-UNICAMP).

ORRADO, I., PILAS,V. e VIVES, J.-M. De l'impossible cession de l'objet voix au possible investissement d'une voix: la passe résonante de l'autiste. In Rev. Latinoamericana de Psicopatologia Fundamental. Vol.20 no.3 São Paulo July/Sept, 2017.

SILVA, C. P. M. Uma cartografia dos usos da noção de reanimação psíquica na psicanálise com bebês e crianças. Dissertação de Mestrado. PUCSP. 2013. Disponível em: https://tede2.pucsp.br/bitstream/handle/15317/1/Caroline\%20Peixoto\%20Mendonca\%20Silva .$p d f$

STERN, D. (1962). O mundo interpessoal do bebê . SP: Artes Médicas, 1992.

VIVES, J.-M. O que torna uma voz tão singular? In Variações psicanalíticas sobre a voz e a pulsão invocante. RJ: Contracapa, 2019.

22 Psicanálise \& Barroco em revista | v.17, n. 01 | julho de 2019 
Just Your Voice - A Voz Como Mediador Privilegiado Na Clínica Com Bebês Em Risco Para Autismo E Na Clínica Com Criançãs Autistas

VIVES, J.-M. Autismo e voz maquínica. Texto inédito, apresentado em 19 de agosto de 2016 na "Jornada com Jean-Michel-Vivès: autismo e voz maquínica" realizada por Outrarte (IELUNICAMP) e LaPSuS (FCM-UNICAMP). 2016.

VIVES, J.-M. Dévoilement, révélation et voilement de la voix. Enjeux invocants de la médiation thérapeutique utilisant la musique. In VINOT et VIVES (org). Les médiations thérapeutiques par l'art. Paris: Érès, 2014.

VIVES, J.-M. A voz na clínica psicanalitica. Rio de Janeiro: Contracapa, 2012. 


\title{
Just Your Voice - Voice As A Privileged Mediator In The Climate With Babies At Risk For Autism And In The Clinic With Autistic CHILDREN
}

\begin{abstract}
From the psychoanalytical notion of the voice, the hypothesis that it is the first object which organizes the bond between the child and the Other, and the hypothesis that the clinic of the autism gives testimony of a specific difficulty in the constitution of the circuit of the invoking drive and the object voice, this article approaches the maneuver of this drive and of the voice as privileged mediators in the clinic with babies in risk for the autism and in the clinic with autistic children.
\end{abstract}

KEYWORDS: psychoanalysis, babies, autism, voice, invoking drive. 


\section{Just Your Voice - Voix En Tant Que Médiateur Privilégié Dans le Climat Avec Les Bébés À Risque Pour L'autisme Et Dans La Clinique Avec Des Enfants Autistiques}

\section{RÉSUMÉ}

A partir de la notion psychanalytique de la voix, de l'hypothèse qu'elle est le premier objet autour duquel s'organise le lien entre l'enfant et l'Autre, et de l'hypothèse que la clinique de l'autisme témoigne une difficulté spécifique dans la constitution du circuit de la pulsion invocante et de l'objet voix, cet article approche le manœuvre de cette pulsion et de la voix comme des médiateurs privilégiés dans la clinique des bébés en risque pour l'autisme et dans la clinique des enfants autistes.

MOTS-CLÉS: psychanalyse, bébés, autisme, voix, pulsion invocante. 
Recebido em: 29-03-2019

Aprovado em: 10-06-2019

(C) 2019 Psicanálise \& Barroco em revista

http://www.seer.unirio.br/index.php/psicanalise-barroco/index

revista@psicanaliseebarroco.pro.br

Programa de Pós-Graduação em Memória Social — UNIRIO

Memória, Subjetividade e Criação

www.memoriasocial.pro.br/proposta-area.php

26 Psicanálise \& Barroco em revista | v.17, n. 01 | julho de 2019 